\title{
Resenha: Brazilian jive, de David Treece
}

\section{SILVANO FERNANDES BAIA*}

\section{Review: Brazilian jive, by David Treece}

TREECE, David. Brazilian jive: from samba to bossa and rap. London: Reaktion Books Ltd., 2013.

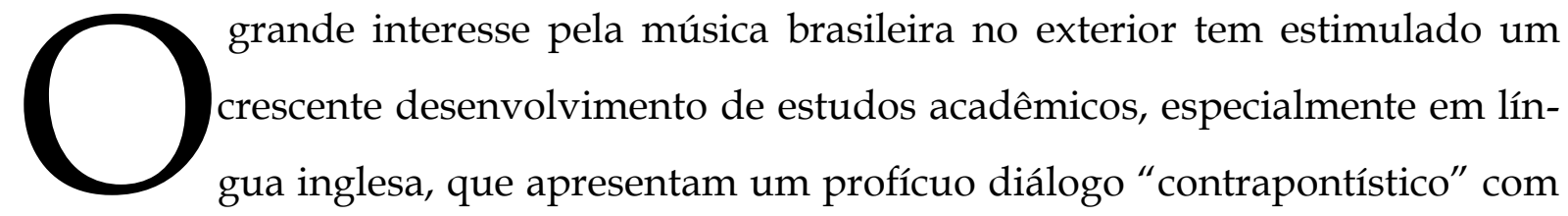
as pesquisas realizadas no Brasil, a exemplo de Brazilian Jive, a mais recente contribuição de David Treece neste campo de estudos. O livro é um estudo da musicalidade e da cultura brasileira, desenvolvido em torno de um conjunto de gêneros fundamentais na música popular do Brasil ao longo do século XX, especialmente o samba, a bossa nova e o rap, mas não se propõe a ser e nem se apresenta como uma história da música popular no país, embora elementos de uma narrativa histórica estejam naturalmente presentes. O que articula o estudo que Treece desenvolve acerca destes gêneros, do que eles significaram e ainda significam nas práticas musicais brasileiras, suas representaç̃os simbólicas e suas transformações ao longo do tempo é um elemento comum de continuidade das tradições africanas no país, que o autor denomina de "afro-brasileiras", em um certo grau de integração ou fricção como os demais elementos constitutivos da cultura brasileira, em especial a herança europeia.

Uma vez que Treece enfatiza o caráter indissolúvel de canção de todos esses gêneros, sua abordagem para o estudo desse material procura contemplar os elementos da estruturação musical, o discurso melódico-harmônico e o tratamento rítmico de uma maneira integrada ao discurso literário e argumento lírico, bem como observar os aspectos sócio-históricos e culturais a eles associados. Em diversos mo-

\footnotetext{
* Silvano Fernandes Baia é Doutor em História Social pela Universidade de São Paulo (2010), mestre em Música pela Universidade Estadual Paulista (2005) e bacharel em Música com habilitação em violão pela mesma instituição (2001). Atualmente é professor adjunto no Instituto de Artes da Universidade Federal de Uberlândia, onde ministra disciplinas de História da Música. Membro do grupo de pesquisa interdisciplinar e interistitucional História e Música, sediado na UNESP-Franca. Email: silvanobaia@gmail.com
} 
mentos do texto, como forma de sustentar suas proposições, o autor desenvolve análises de canções, nas quais, sem prejuízo da consistência da argumentação ou reduções simplistas, é nítida a preocupação de tornar estas análises acessíveis a um público leigo em teoria musical ou literária. Nesse sentido, se utiliza não apenas da representação gráfica da relação melodia/letra desenvolvida por Luiz Tatit, como oferece traduções para o inglês que permitem o entendimento do argumento lírico original, num esforço para evitar a perda estética e semântica que ocorreu nas versões que popularizaram a bossa nova no exterior nos anos 1960. Treece mobiliza um amplo conjunto de referenciais teóricos e metodológicos desenvolvidos para a análise da canção e da cultura brasileira e africana, bem como suas próprias elaborações nesse campo de estudo, dialogando tanto com trabalhos de pesquisadores brasileiros, a exemplo de Muniz Sodré, José Miguel Wisnik, Luiz Tatit, Claudia Matos, Hermano Vianna e Carlos Sandroni, entre outros, como com pesquisas realizadas no hemisfério norte, trabalhos muitas vezes desconhecidos pelos pesquisadores no Brasil. Com o conhecimento da literatura brasileira de quem desenvolveu um estudo de fôlego sobre o indianismo no romantismo brasileiro e a política indigenista no período imperial (TREECE, 2008), o autor pontua o seu texto com algumas poucas mas saborosas e enriquecedoras citações literárias, de Graciliano Ramos, Guimarães Rosa e Carlos Drummond de Andrade.

O livro está estruturado em seis capítulos. O primeiro - Brazilian jive talk: music, language and community - apresenta uma discussão introdutória acerca da cultura musical do Brasil, bem como delineia o arcabouço teórico a partir do qual será construída a argumentação. $\mathrm{O}$ autor alinhava através de elementos recorrentes na historiografia do samba, um discurso que apresenta o gênero como oriundo de um pensamento musical, cultural e filosófico africano, constituindo-se assim em manifestação de resistência cultural negra. A seguir, esboça a ideia que será desenvolvida nos capítulos posteriores, de que é possível localizar na bossa nova, na MPB e mais recentemente no rap um fio de continuidade de resistência cultural e afirmação identitária negra, que, se não chega a ser totalmente inovadora em relação a estudos realizados no Brasil, é bastante acurada na sua linha de argumentação. O segundo capítulo - The bossa nova revolution - está dedicado a observar a repercussão e o impacto 
das transformações estéticas apresentadas pela bossa nova, oferecendo uma interpretação para o seu sucesso e longevidade. Em Three masters, three master-pieces: Jobim, Moraes, Gilberto - o terceiro capítulo -, Treece observa o projeto estético destes autores/intérpretes, concretizando este estudo na análise de três peças emblemáticas: "Garota de Ipanema”, "Felicidade” e "Águas de Março". No quarto capítulo - Guns and roses: Brazil's music of popular protest, 1958-1968 - após situar o ambiente sociocultural e político do final dos anos 1950 e anos 1960 no país, bem como pontuar as transformações produzidas nos meios de comunicação e circulação de bens culturais, Treece passa em revista os conturbados eventos musicais do período e as lutas político-culturais a eles associadas. Em Orpheus in Babylon: music in the films of Rio de Janeiro, o quinto capítulo, o autor observa a presença da música na produção fílmica em torno da cidade do Rio de Janeiro. Ainda que outros filmes sejam mencionados, o foco está em dois filmes que, em momento distintos, adaptaram o mito clássico de Orfeu transpondo-o para o Rio de Janeiro: a produção franco-brasileira Black Orpheus, dirigido por Marcel Camus (1959) e Orfeu, de Cacá Diegues (1998). No sexto e último capítulo, Rap, race and language: the aesthetics and politics of black music-making, Treece observa o fenômeno da emergência de uma poderosa cultura musical no Brasil, aquela constituída em torno de elementos do soul, do rap, do hip-hop e do funk carioca, uma música dançante, com baixos pesados, batidas eletrônicas e um discurso de descontentamento social, que circularia, principalmente mas não exclusivamente, entre jovens afro-brasileiros das classes trabalhadoras. A ascensão destas novas formas de manifestação cultural por parte de jovens negros pobres, estaria vinculada ao colapso do projeto de harmonização social e democracia racial, que teria se explicitado por volta da década de 1990.

Duas linhas de pensamento articulam os temas desenvolvidos nestes capítulos. Ao longo de todo o texto está presente a concepção de que nesses gêneros de música popular do Brasil, especialmente no samba, na bossa nova e no rap, existiria um fundamento cultural e filosófico de origem africana. Ou seja, elementos da cultura e da visão de mundo da África ocidental estariam presentes, de diversas formas, em distintas gerações e diferentes contextos, na música produzida pelos afrodescendentes no Brasil ou mesmo por brancos das classes médias com vínculos com 
a cultura africana. A outra proposição que orienta o discurso de Treece é a de que esses gêneros não podem ser compreendidos plenamente sem a percepção do seu caráter cancional, ou seja, todas estas práticas musicais têm que ser pensadas nas suas interações entre elementos musicais e texto literário, considerando-se também o contexto sócio-histórico.

Treece questiona a concepção corrente de que Brasil seria uma cultura essencialmente musical em comparação com outras culturas supostamente mais letradas e literárias, proposição esta que estaria ancorada na ideia de que a força da cultura musical do país seria uma contraparte da relativa pobreza e fraqueza da cultura linguística. Essa ideia, por sua vez, seria afinada com a concepção de que o alto nível da música e da dança nas culturas da diáspora africana seria derivado da sua "oralidade" e "corporalidade", uma vez que suas tradições linguísticas teriam sido suprimidas pela escravidão, ou, em termos mais racistas, porque a essência da "africanidade" residiria no corpo, em contraste com a mais cerebral e racional cultura europeia. Treece se contrapõe a essa ideia, que considera uma das grandes falácias acerca das expressões culturais da diáspora africana, e afirma que a linguagem - seja em textos religiosos, narrativas, canções ou versos improvisados - tem um papel central e não periférico nessas culturas. De maneira diametralmente oposta a essas afirmativas, o autor considera que a musicalidade brasileira se desenvolveu justamente por sua interação com uma rica inventividade linguística.

Treece recapitula uma narrativa tradicional em torno das origens do samba carioca na qual tem destaque a "roda", como elemento da cultura africana, numa linha interpretativa que foi inaugurada no texto clássico de Francisco Guimarães (Vagalume) Na roda do samba (1933). Entre outros ícones mencionados, tais como a Praça Onze, a casa da tia Ciata, "Pelo telefone" e "Lenço no pescoço", tem destaque o papel da "malandragem". A sincopação do samba seria a expressão musical da ginga do malandro, numa elaboração que remete diretamente à Muniz Sodré (1979). Aliás, a malandragem está destacada no título do livro, uma vez que o termo norteamericano "jive" foi a melhor aproximação que Treece encontrou para a tradução de "malandragem" para o inglês. Ao enfatizar um aspecto de resistência cultural negra do gênero e não uma condição de produto de um encontro de culturas, o autor se po- 
siciona num debate que remete aos anos 1930, que se intensificou com o surgimento das pesquisas acadêmicas sobre música popular no Brasil a partir dos anos 1970 e que é ainda uma questão em aberto. Conforme Marcos Napolitano, já nos anos 1930 “as discussões sobre a música popular se pautaram ora pela busca de uma 'raiz' social e étnica específica (os negros), ora pela busca de um idioma musical universalizante (a nação brasileira)", que seriam a base de duas linhas mestras do debate historiográfico que se desenvolve desde então (2006, p.136).

Na sua análise da bossa nova e da longevidade do seu sucesso internacional, Treece se diz convencido de que a fascinação que o gênero desperta deriva do profundo hibridismo na composição e performance das canções, combinando as duas maiores dimensões civilizacionais da formação histórica do Brasil: a direcionalidade narrativa das tensões e resoluções características da música ocidental com o universo musical das tradições africanas, sem privilegiar nenhuma delas. Uma vez que na bossa nova mais uma vez se abriu a possibilidade de diálogo entre linguagem literária e música sempre presente na cultura brasileira, o gênero apenas pode ser plenamente compreendido se considerado o seu aspecto de canção, que muitas vezes é negligenciado devido aos diversos caminhos e apropriações ao longo do tempo em diferentes lugares. Aqui é muito interessante observar como Treece comenta a percepção do gênero no exterior, por uma parcela dos ouvintes, como banalidade de dúbio valor artístico, uma forma de muzak ou easy listening para elevadores, supermercados, shoppings, salas de espera e aeroportos, percepção esta que seria decorrência de seu grande sucesso comercial e ubiquidade. Esta é uma apreensão que só se pode ter a partir do hemisfério norte, onde, de fato, em alguns países e ambientes, o gênero tem essa utilização de música de fundo, o que não ocorre no Brasil. Treece argumenta que a mediação do jazz estadunidense na disseminação internacional da bossa nova levou à transformação de um gênero cancional em um estilo instrumental, com consequente desmembramento das complexas relações estruturais entre o tratamento melódico-harmônico, o movimento rítmico e o argumento discursivo e sua vocalização, o que teria facilitado o caminho para essa reformatação do gênero como easy listening. Naturalmente, isto não impede que a bossa nova continue despertando interesse em outra parcela do público, mesmo entre as novas gerações. 
O fenômeno da emergência de uma poderosa cultura musical no Brasil, aquela constituída em torno de elementos do soul, do rap, do hip-hop e do funk carioca é analisado pelo autor no último capítulo. Treece considera que esta tendência musical desafia a concepção do Brasil como uma sociedade cuja suposta capacidade de integração na superação de antagonismos sociais e étnicos tem sua expressão cultural maior no carnaval e no samba. A bossa nova e a MPB estariam também associadas à ideia de uma democracia social, baseada na aliança entre distintos setores. Portanto, o samba, a bossa nova e a MPB não serviriam mais de veículos para uma juventude que buscava uma afirmação identitária como "negros" e não apenas como "brasileiros", uma vez que a partir dos anos 1990 teria ocorrido um colapso dessa "cultura do consenso". Para Treece, apesar do estímulo inicial de gêneros musicais estadunidenses para essas novas formas de manifestação musical no Brasil, elas mantém um fio de continuidade com as tradições dos afrodecendentes no país, que se expressaria na habilidade de materializar o poder das palavras num tempo ritmicamente estruturado. Assim o rap retomaria uma estética musical negra no sentido de que as expressões corporais e linguísticas, assim como o ritmo e o discurso, não são contrapostos mas integrados num mesmo produto artístico. O livro conclui com uma complexa e polêmica discussão a favor da proposição e do conceito que alinhava toda a narrativa desenvolvida ao longo texto, da existência de uma identidade musical negra no Brasil. No debate que Treece estabelece com as visões que enfatizam de maneira positiva a integração do negro na sociedade brasileira a partir do conceito de mestiçagem, o autor vai concluir que os afrodescendentes nunca deixaram de ser uma subcategoria discriminada racialmente nessa sociedade. Observa que o termo negro foi adotado pelos afrodescendentes como uma forma de identificação como o passado e as tradições afro-brasileiras. E nesse espírito, insiste na formulação "música negra", entendida não como uma categoria essencialista, mas como um veículo das noções de consciência, atuação e resistência.

O estudo apresentado por David Treece se insere e se posiciona não apenas no debate em curso em torno da música popular no Brasil, como na discussão mais ampla acerca da cultura do país e suas complexas conexões com questões étnicas e identitárias. Treece se soma à crítica das posições de Gilberto Freyre levada a 
cabo por diversos pensadores de esquerda a partir dos anos 1960 e pelo movimento negro contra a discriminação que, surgido no final dos anos 1970, vem apresentando um discurso militante radicalizado sobre a questão, em geral vinculado a agendas políticas. O lugar de Gilberto Freyre na construção do pensamento sobre a formação da sociedade brasileira é um grande e antigo debate e a persistência dessa crítica atesta também a repercussão de suas ideias. Freyre apresentou uma visão positiva da mestiçagem, vendo nela a originalidade da cultura brasileira, num momento, os anos 1930, em que ainda era hegemônica a concepção de que a mestiçagem estaria na raiz dos problemas da nossa sociedade, que deveria ser aprimorada pelo branqueamento. Desde então, a ideia de que o brasileiro seria uma "raça mestiça" e que nisso residiria a sua força e originalidade, afirmou-se como uma das vertentes de interpretação da nossa cultura. Naturalmente, não se trata de negar a existência de racismo no Brasil, ao longo da história e no presente. Existiu e ainda existe, sem dúvida. Mas existe também, indubitavelmente, a tendência à integração. As duas tendências existem e o problema colocado para o Brasil é qual delas vamos favorecer. A difícil questão que se apresenta é até que ponto a afirmação de identidades étnicas, por vezes de maneira um tanto forçada e com aspectos de invenção de tradição, não caminha no sentido contrário de uma efetiva integração, servindo até como elemento de divisão em direção a uma sociedade bipartida, coisa que o Brasil hoje não é, apesar de todos os seus problemas.

No debate mais propriamente musical, de certa forma, Treece reafirma, com argumentação refinada e renovada, uma linha de pensamento presente nos estudos da música popular no Brasil desde os primeiros ensaios acadêmicos dos anos 1970, que enfatizavam o aspecto de resistência cultural na música popular. Estas posições contrastam com pesquisas desenvolvidas no Brasil que apresentaram outros olhares para essas mesmas questões. ${ }^{1}$ Por exemplo, Hermano Vianna (1995), em O mistério do samba (que Treece cita e inclui como indicação de leitura entre os títulos publicados em inglês), analisa a transformação do samba em música nacional como parte de um processo mais amplo de criação da identidade brasileira em torno do

\footnotetext{
${ }^{1}$ Na minha tese de doutorado (BAIA, 2010) desenvolvi um amplo estudo da historiografia da música popular no Brasil, no qual apresentei um mapeamento das principais linhas de pensamento e das polêmicas em curso nesse campo de estudos dentro da periodização da pesquisa.
} 
debate sobre a miscigenação "racial" e cultural e valorização da cultura popular, apresentando outra vertente interpretativa que se contrapõe à narrativa da "resistência cultural". No trabalho de Vianna, as proposições de Gilberto Freyre, criticadas por Treece, são tomadas como instrumental teórico privilegiado. Um outro exemplo é o trabalho de Tiago de Melo Gomes (1998), que questiona o papel central da malandragem na história do samba e considera a publicação de Acertei no milhar, de Claudia Matos (1982), um momento crucial na transformação do que ela chamou de "samba malandro" em discurso das camadas oprimidas da sociedade em oposição ao projeto das classes dominantes de implantação do capitalismo no Brasil. Por outro lado, estudos recentes vêm se debruçando sobre outros gêneros e repertórios, questionando a hegemonia da linhagem samba-bossa-MPB-tropicália que, à exceção da pertinente discussão acerca das sonoridades do rap e do funk a partir dos anos 1990, está também no centro de Brazilian Jive. O livro tem um objeto mais específico, que é a presença de elementos da cultura africana em gêneros fundamentais da música do Brasil, e não se propõe a ser uma história da música no Brasil nem a dar conta de toda a diversidade da produção musical brasileira. De toda forma, a seleção das fontes, no caso, os gêneros e o repertório específico em estudo, favorece o direcionamento que o autor imprimiu à sua narrativa.

Brazilian Jive, livro voltado para um público de língua inglesa interessado em música brasileira, é uma leitura instigante também para pesquisadores brasileiros, conhecedores dos fatos em discussão, pelas reflexões, releituras e profícuas elaborações que oferece. Em Brazilian Jive podemos ver o entusiasmo de David Treece com a música popular e a cultura do Brasil. Seu trabalho de divulgador e aglutinador de pesquisadores brasileiros, e também de outras nacionalidades, interessados na música brasileira, em iniciativas que não se restringem à atuação acadêmica, mas também têm ramificações no campo de produção, o colocam hoje como a principal referência para os estudos da música popular do Brasil no exterior. Suas posições, pela força e consistência da sua argumentação, bem como por partirem de alguém profundamente envolvido com a prática e a pesquisa da música brasileira a partir do King's College London, têm que ser consideradas no debate, independentemente do grau de concordância ou discordância que se possa ter com sua linha de pensamento. 


\section{Referências}

BAIA, Silvano Fernandes. A historiografia da música popular no Brasil (1971-1999). Tese (doutorado em História) - FFLCH-USP, São Paulo, 2010.

GOMES, Tiago de Melo. Lenço no pescoço: o malandro no teatro de revista e na música popular - "nacional", "popular" e cultura de massas nos anos 1920. Dissertação (mestrado em História) - IFCH-UNICAMP, Campinas, 1998.

GUIMARÃES, Francisco (Vagalume). Na roda de samba. Rio de Janeiro: Typ. São Benedicto, 1933.

MATOS, Claudia Neiva. Acertei no milhar: samba e malandragem no tempo de Getúlio. Rio de Janeiro: Paz e Terra, 1982.

NAPOLITANO, Marcos. A historiografia da música popular brasileira (19701990): síntese bibliográfica e desafios atuais da pesquisa histórica. ArtCultura. Uberlândia: Edufu, v.8, nº 13, 2006, p.136.

SODRÉ, Muniz. Samba: o dono do corpo. Rio de Janeiro: Codecri, 1979.

TREECE, David. Exilados, aliados, rebeldes: o movimento indianista, a política indigenista e o Estado-nação imperial. São Paulo: Nankin/Edusp, 2008.

VIANNA, Hermano. O mistério do samba. Rio de Janeiro: Zahar, 1995. 